\title{
The Relationship of Secretion and Activity of Recombinant Factor IX with N-Glycosylation
}

\author{
Samira Khalilzadeh ${ }^{1}$ (D, Jafar Vatandoost ${ }^{1 *}$ (D)
}

1. Department of Biology, Faculty of Sciences, Hakim Sabzevari University, Sabzevar, Iran.

$\begin{gathered}\text { Use yur devic to scan } \\ \text { and read thearticle online }\end{gathered}$
Sylation. Research in Molecular Medicine. 2020; 8(1):31-36. https://doi.org/10.32598/rmm.8.1.31
dol https://doi.org/10.32598/rmm.8.1.31

\section{(i) (\$)}

Article Type:

Research Article

Article info:

Received: 22 Dec 2019

Revised: 19 jan 2020

Accepted: 29 jan 2020

\section{Keywords:}

Blood Coagulation Factor

IX, N-glycosylation,

Tunicamycin, Protein folding

\begin{abstract}
A B S T R A C T
Background: Human coagulation factor IX (hFIX) is a glycoprotein with two N-glycosylation sites at the activation peptide. Since the activation peptide is removed in mature hFIX, the exact role of $\mathrm{N}$-glycosylation is unclear. To investigate the role of $\mathrm{N}$-glycosylation in the secretion and activity of hFIX, we inhibited N-glycosylation by tunicamycin in the stable Human Embryonic Kidney (HEK)coagulation Factor IX (FIX) cells.
\end{abstract}

Materials and Methods: After the treatment of stable FIX-expressing HEK cells in the presence or absence of tunicamycin, the expression and activity of the recombinant FIX (rFIX) were determined in culture medium and cell lysate with enzyme-linked immunosorbent assay and clotting test, respectively.

Results: Based on the data analysis, total concentrations of FIX in stable HEK-FIX was the same in the media with and without tunicamycin. But throughout the post-induction period, the intracellular and secreted levels of FIX in tunicamycin-treated HEK-FIX cells increased and decreased, respectively, compared with those of control HEK-FIX cells, though the results were not significant. These results indicate that disrupting the synthetic process may slightly reduce the FIX levels secreted in HEK-FIX cells.

Conclusion: Although glycosylation plays a vital role in the folding and secretion of the proteins, it does not affect the secretion of FIX. Besides, the N-glycosylation of the produced FIX failed to play a significant role in its activity.

\section{Introduction}

ecretory proteins may pass through a series of Post-Translational Modifications (PTM) before reaching the final destination. These changes may cause proteins to fold into their natural structures and to expose their structural stability to the extracellular environment $[1,2]$. Among the different PTMs, N-glycosylation is an essential one in the majority of secretory proteins [3, 4], and it is involved in various processes of folding, stability, and secretion [5]. Correct folding in proteins is an essential biological process; without it, the normal function of proteins is impaired or lost [6].

* Corresponding Author:

Jafar Vatandoost, PhD.

Address: Department of Biology, Hakim Sabzevari University, Sabzevar, Iran.

Phone: +98 (51) 44013329

E-mail:j.vatan@hsu.ac.ir; jafar.vatandoost@gmail.com 
Also, the appropriate folding is necessary for exporting the secretory proteins from the Endoplasmic Reticulum (ER) to the Golgi apparatus and then secreting out of the cell [7]. Thus, the inhibition of N-glycosylation (as a necessary PTM) results in the accumulation of incorrectly folded proteins within the ER $[8,9]$.

ER is where proteins enter the secretory pathway and a checkpoint for their folding and secretion. ER offers a level of quality control on exporting protein, which only allows for the secretion of correctly folded and modified proteins [10]. Proteins that fail to achieve their native structures (correct glycosylation and therefore right folding) are kept in the ER, where they are targeted for retro-translocation into the cytosol and degraded by the proteasome [10]. Accordingly, the N-glycosylation of recombinant proteins, especially those with pharmaceutical applications, is regarded as one of the major concerns when they are exposed to over-production [11-13].

Blood coagulation factor IX (FIX), as a single polypeptide chain, consists of several distinct domains such as the gamma-carboxyglutamic, two tandem copies of the epidermal growth factor, and activation and serine protease domains. This plasma glycoprotein is secreted from the liver into the blood and circulated as a zymogen, an inactive precursor. If necessary, it is processed to remove the activation peptide to produce a two-chain form linked by a disulfide bridge [14]. Human FIX zymogen includes two potential N-glycosylation sites at Asn157 and Asn167 and six potential O-glycosylation sites at Ser61, Ser63, Thr172, Thr169, Thr159, and Thr179 [15, 16].

Obviously, six positions located in the activation domains (amino acids 146-180) are removed proteolytically. Since both N-glycosylation sites occur in the activation domain and are absent in the active enzyme, the enzymatic activity of FIX may not be affected by the $\mathrm{N}$-glycan structures. However, other essential functions have not been considered suggesting that the N-glycans are necessary for the prolongation of circulating zymogen [17-19]. On the other hand, N-linked glycosylation is principally vital because of influencing some properties such as folding and secretion [20]. Hence, the present study aimed to investigate the effects of FIX $\mathrm{N}$-glycans on enzyme activity, along with the FIX expression and secretion.

\section{Materials and Methods}

\section{Cell culture}

Stable HEK-FIX cells were maintained in DMEM-F12 medium (Gibco) supplemented with 10\% fetal bovine serum (Capricorn) and 1\% penicillin/streptomycin (Sig$\mathrm{ma}$ ) in the presence of $450 \mu \mathrm{g} / \mathrm{ml}$ Geneticin (Sigma) and were incubated at $37^{\circ} \mathrm{C}$ with $95 \%$ humidity and $5 \% \mathrm{Co}_{2}$. In order to express recombinant FIX, the stable HEKFIX cells were subcultured at a density of $2 \times 105$ cells in a volume of $2 \mathrm{ml}$ in 6 -well plates. The expression media including $6 \mu \mathrm{g} / \mathrm{ml}$ vitamin $\mathrm{K} 1$ (Roche) was added to $\sim 70 \%$ confluent cells. In addition, the FIX-expressing HEK cells were cultured in the absence or presence of tunicamycin $(5 \mu \mathrm{g} / \mathrm{ml})$ in order to evaluate the effect of N-glycosylation inhibition. Finally, the expression and activity of FIX were analyzed in the intracellular and conditioned media after three days.

\section{Immunoassay of the expressed FIX}

The FIX was quantified in a conditioned media by implementing an ELISA (Asserachrom IX:Ag, Stago, France) followed by the procedure provided by the manufacturer. The strip wells were pre-coated with goat polyclonal antibody for human FIX. In the next stage, the samples were diluted, among which $100 \mu \mathrm{l}$ of the text sample were applied to the wells. After a 30-min incubation of the present FIX, the antigen was bound to the coated antibody, the unbound material was washed away, and $100 \mu \mathrm{l}$ peroxidase-labeled goat detecting antibody was applied and allowed to bind to the captured FIX for $30 \mathrm{~min}$. The wells were washed again and a solution of TMB $(100 \mu$ l of peroxidase substrate tetramethylbenzidine) was utilized and allowed to react for $10 \mathrm{~min}$. Accordingly, a blue color developed changing intoyellow upon quenching the reaction with $100 \mu \mathrm{l}$ of $0.2 \mathrm{M}$ sulphuric acid. Finally, the color formed was spectrophotometrically measured in a microplate reader at 450 $\mathrm{nm}$. In addition, the absorbance at $450 \mathrm{~nm}$ was directly related to the concentration of FIX based on the standard curve and stated in ng/mL. Further, the assay was calibrated using the calibrator plasma provided in the kit. Furthermore, the results obtained from the subtraction of non-specific absorbance were determined based on the non-transfected cells.

The intracellular accumulated FIX was assessed, by which the cells were pelleted by centrifugation at $100 \mathrm{~g}$ for 5 minutes, and they were suspended again in $500 \mu \mathrm{L}$ of ice-cold lysis buffer $(100 \mathrm{mM} \mathrm{KCl}, 2 \mathrm{mM}$ $\mathrm{MgCl} 2,10 \mathrm{mM}$, HEPES pH 7.5, 0.5\% Triton X100) in- 
cluding an antiprotease mix (complete Protease Inhibitor, Roche). Subsequently, the lysate was centrifuged at $12,000 \mathrm{~g}$ for $10 \mathrm{~min}$ at $4^{\circ} \mathrm{C}$, upon which the supernatant was assessed for FIX.

\section{Activity and specific activity analysis of FIX}

The functional activity of FIX is examined by using an aPTT assay (activated partial thromboplastin time) ( HYPERLINK $\backslash 1$ "21). First, the human plasma immunodepleted of FIX (100 $\mu \mathrm{L}$; Stago) was mixed with the conditioned media $(100 \mu \mathrm{L})$ and aPTT reagent $(100 \mu \mathrm{L}$; BioMerieux). Then, $100 \mu \mathrm{L}$ of the pre-warmed $\mathrm{CaCl} 2$ solution $(25 \mathrm{mM})$ was added to the mixture after 3-mi incubation at $37^{\circ} \mathrm{C}$ and accordingly the clotting time was recorded. FIX activity was calculated using a standard curve of normal pooled plasma (prepared from the Iranian blood transfusion organization), followed by correcting the nonspecific clotting activity determined from the non-transfected cells. Moreover, the specific activity of FIX as the activity per quantity was determined by the ratio of activity per FIX antigen.

\section{Statistical analysis}

All the experiments were conducted in triplets. ANOVA, followed by a Tukey post-hoc test, was used for data analysis. $\mathrm{P}<0.05$ was considered as statistically significant.

\section{Results}

Although the authors have already confirmed the inhibition effect of tunicamycin on the N-glycosylation of FIX [21], no research is available concerning the impact

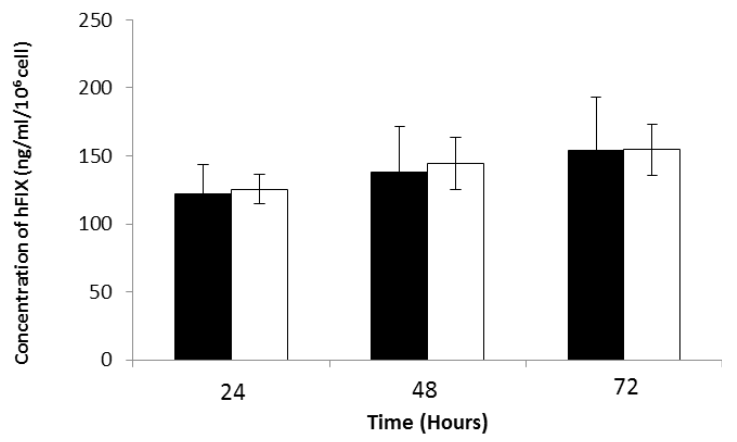

क्pmm

Figure 1. The total concentration of secreted human coagulation Factor IX (hFIX) in the Human Embryonic Kidney (HEK) cells with ( $\bullet$ ) and without ( $\square$ ) tunicamycin. Following preparation of stable coagulation Factor IX (FIX) producing HEK cells, intracellular and secreted FIX were assessed in the conditioned media with ( $\bullet$ ) or without tunicamycin ( $\square$ ) by ELISA during $72 \mathrm{~h}$ of post-induction with $6 \mathrm{mg} / \mathrm{mL}$ vita$\mathrm{min} \mathrm{K} 1$. The data are the means of three similar experiments. of N-glycosylation on the activity and expression of FIX. Therefore, both intracellular and cultured media were examined for FIX antigen levels for $72 \mathrm{~h}$ after tunicamycin treatment to evaluate the effect of N-glycosylation on the expression of FIX in the stable HEK-FIX. Based on the results, a slight increase and decrease occurred in intracellular and secreted levels of FIX in tunicamycin treated HEK-FIX cells, respectively, compared with those of the control HEK-FIX cells. On the other hand, total concentrations of FIX in stable HEK-FIX was similar in media with and without tunicamycin (Figure 1).

Meanwhile, the intracellular levels of FIX in the stable HEK-FIX cells reached up to $49 \mathrm{ng} / \mathrm{mL} / 10^{6}$ cells. The amount of FIX in cell lysis of tunicamycin-treated HEKFIX cells increased over time and amounted to $63 \mathrm{ng} /$ $\mathrm{mL} / 10^{6}$ cells. On the other hand, as illustrated in Figure 2 , the amount of the secreted FIX decreased in tunicamycin-treated HEK-FIX cells, compared with that in HEK-FIX cells (90 vs $105 \mathrm{ng} / \mathrm{mL} / 106$ cells). This finding suggests that the inhibition of N-glycosylation of FIX could prevent or slightly reduce its secretion to medium, though the difference was not significant $(\mathrm{P} \geq 0.05)$.

\section{Biological activity of the expressed FIX}

The clotting activity of FIX was assessed in the media of HEK-FIX cells at different time intervals. The FIX secreted from tunicamycin-treated HEK-FIX cells showed a clotting activity up to $17 \mathrm{mU} / \mathrm{mL}$ after 3 days of postinduction, which failed to indicate a significant difference ( $\mathrm{P} \geq 0.05)$, compared with the FIX activity level (19 $\mathrm{mU} / \mathrm{mL}$ ) obtained for HEK-FIX cells (Figure 3 ).

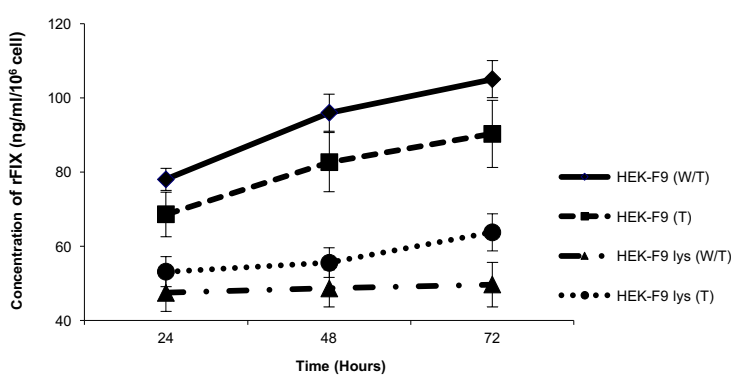

grmm

Figure 2. The comparison of coagulation factor IX (FIX) secretion efficiency with $(\mathrm{T})$ and without $(\mathrm{W} / \mathrm{T})$ tunicamycin. The human coagulation factor IX (hFIX) in cell lysate and the supernatant were determined with ELISA during 72h of post-induction in Human Embryonic Kidney (HEK)-hFIX. Based on the results of the independent $t$ test for ELISA, no significant difference was observed between with and without tunicamycin stable cells $(\mathrm{P}<0.05)$. 


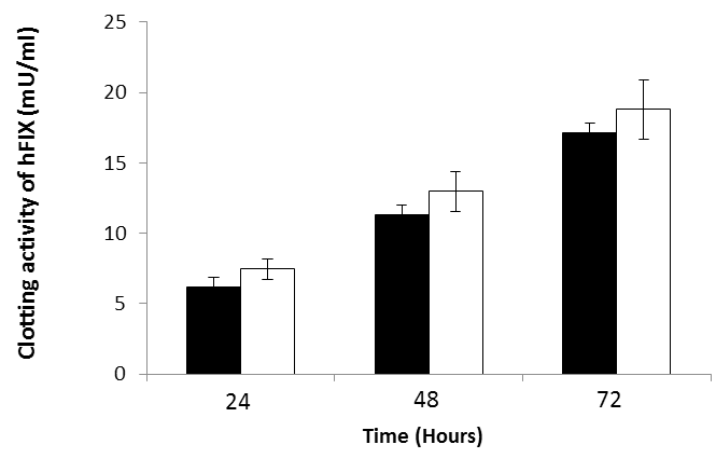

grmm

Figure 3. The comparison of coagulation Factor IX (FIX) clotting activity in the stably Human Embryonic Kidney (HEK) cells with ( $\bullet$ ) and without $(\square)$ tunicamycin assessed with coagulation test. The secreted human coagulation Factor IX (hFIX) in conditioned media was examined in 3 days of postinduction. The Partial Thromboplastin Time (PTT) clotting test was used to investigate the hFIX clotting activity of the cultured media. Normal pooled human plasma was used as the standard. According to the results, the difference observed between treated and untreated cells was not significant. A plasma concentration of $\sim 5 \mu \mathrm{g} / \mathrm{mL}$ of FIX is equal to 1 International Unit (IU).

\section{Assessment of FIX specific activity}

As illustrated in Figure 4, the particular activities of FIX secreted by tunicamycin-treated HEK-FIX cells are equal to $0.09,0.136$, and $0.189 \mathrm{mU} / \mathrm{ng}$ at 24,48 , and $72 \mathrm{~h}$, respectively. However, those of FIX in HEK-FIX cells at these times were $0.095,0.135$, and $0.178 \mathrm{mU} / \mathrm{ng}$, respectively. Thus, the FIX secreted from both cell types could display an equal specific activity.

\section{Discussion}

Folding into the native structure and modification of newly synthesized polypeptides are essential for the export of secretory proteins to the Golgi apparatus [22]. $\mathrm{ER}$, like a quality control system, monitors the folding status of transiting polypeptide chains. Incorrectly folded proteins are kept inside the ER until they can regain their normal structure [22]; otherwise, they are translocated to the cytosol and degraded by the proteasome [9]. For controlling this mechanism, the attached protein chaperone to the ER membrane, called "calnexin," first detects proteins with uncorrected folding through the end glucose existing on $\mathrm{N}$-oligosaccharides [23].

Since N-glycosylation may play a significant role in trapping or secreting recombinant proteins, the present study focused on evaluating the N-glycosylation function in the expression and secretion of FIX through the

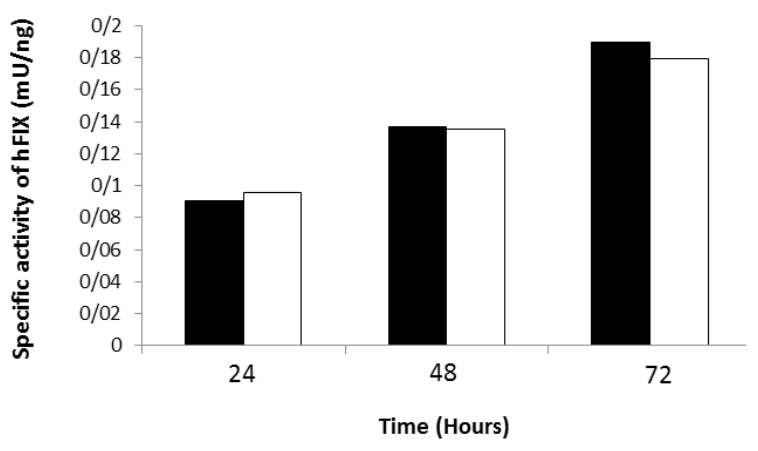

कrmm

Figure 4. The specific activity assessment of human coagulation factor IX (hFIX) secreted in the culture medium of the Human Embryonic Kidney (HEK)-hFIX with (ロ) and without ( $\square$ ) tunicamycin. The specific activity of hFIX as the activity per quantity was determined by the ratio of activity per FIX antigen.

inhibition of N-glycosylation by tunicamycin. We used tunicamycin since non-N-glycosylated FIX has been provenly produced after tunicamycin treatment. The SDS-PAGE analysis of recovered FIX by barium citrate adsorption from culture media indicated that tunicamycin could block N-glycosylation [21]. On the other hand, the N-glycosylation of FIX occurs in the activation peptide, so the existing $\mathrm{N}$-glycosylation in the activation domain of FIX may not affect the related activity [16] Therefore, the activity of the secreted FIX was taken into consideration following the tunicamycin treatment.

According to our results, no significant difference was observed in the total expression of FIX (media and intracellular) in HEK cells when they were treated with or without tunicamycin. Although the concentration of FIX in the cell lysate of tunicamycin-treated cells was more than the case without tunicamycin ( $53 \mathrm{vs} 47 \mathrm{ng} / \mathrm{mL}$ ), the results of FIX expression in the cultured medium confirmed that the FIX concentration was relatively low $(68 \mathrm{ng} / \mathrm{mL})$ in tunicamycin-treated cell media compared with the case without tunicamycin $(78 \mathrm{ng} / \mathrm{mL})$.

Regarding the concentrations of FIX, an increase in cell lysate and a decrease in the media of tunicamycintreated cells indicated that the inhibition of N-glycosylation could almost influence the formation and folding of synthesized proteins and prevent or slightly reduce their secretion to the medium. Considering no significant difference, the inhibition of FIX N-glycosylation barely affects its secretion.

Regarding the role of $\mathrm{N}$-glycosylation in the secretion, some of the secretory proteins were adequately folded 
and transported to their final destination despite the lack of N-glycosylation, which is consistent with findings of some other studies. As for the role of N-glycosylation in the secretion of $\gamma$-interferon, the results indicate that $\mathrm{N}$-glycosylation could slightly affect the secretion. However, the effect of N-glycosylation on secreting the protein relies on its position, and all $\mathrm{N}$-glycosylation sites cannot similarly influence the protein yield and production [24]. Likewise, recombinant erythropoietin and fibronectin, which naturally lack N-oligosaccharides, were reportedly secreted with the same amount, compared with the glycosylated one [25]. In the presence of tunicamycin, however, such proteins as hemagglutinin do not fold properly and remain in the ER [25]. These results suggest that glycan chains induce proper folding and secretion in some secretory proteins and only induce stabilization in others.

Besides, FIX in the media of tunicamycin-treated cells had less activity than that without tunicamycin cells. Therefore, tunicamycin could considerably reduce the activity of FIX in these cells by inhibiting N-glycosylation, though no significant difference was observed between these two modes. Furthermore, the specific activity of the secreted FIX was assessed for better interpretation. The results indicated a slight variation in the particular activity of FIX in cells treated with or without tunicamycin. Since the specific activity, calculated from the ratio of activity to FIX concentrations, is approximately equal in both cases, the non-significant difference in FIX activity is not related to the effect of N-glycosylation, but it relies on the change in the number of FIX secreted into the medium.

Although the effect of FIX N-glycans on protein performance is unclear yet, few studies have focused on the N-glycans effect on FIX function. A possible role for $\mathrm{N}$-glycans in determining the clearance of FIX suggests that hyper-glycosylation decreases clearance and prolongs the circulation of FIX [19]. Moreover, although the enzymatic removal of sialic acid was reported to increase the clearance of wild-type recombinant FIX, no effect was observed on its pre-coagulation activity [26]. Since the N-glycosylation of FIX occurs in Asn157 and Asn167 sites of the activation domain, which is removed after activation in mature FIX, N-glycosylation may not play a significant role in FIX activity.

\section{Conclusion}

Based on the results, the expression level of secreted FIX is not sensitive to inhibition of the N-linked glycosylation by tunicamycin (which is an N-linked glycosyl- ation inhibitor). These results provide some convincing evidence that N-glycosylation cannot play any significant role in FIX secretion levels. Also, the N-glycosylation of the produced FIX has a non-significant effect on its activity. Despite the need for further experimental studies, the evidence provided here suggests that non-Nglycosylated FIX can be appropriately folded and transported to its final destination. We recommend that the role of glycosylation is investigated further by removing single or combined glycosylation sites.

\section{Ethical Considerations}

\section{Compliance with ethical guidelines}

All ethical principles were considered in this article. this article does not contain any studies with human participants or animals.

\section{Funding}

This work was funded by the University of Hakim Sabzevari (2016).

\section{Authors contribution's}

Performing the experiment: Sanira Khalilzadeh; Supervision: Jafar Vatandoost.

\section{Conflict of interest}

The authors declared no conflict of interest.

\section{Reference}

[1] Walsh G, Jefferis R. Post-translational modifications in the context of therapeutic proteins. Nat Biotechnol. 2006; 24(10):1241-52. [DOI:10.1038/nbt1252] [PMID]

[2] Walsh G. Post-translational modifications of protein biopharmaceuticals. Drug Discov Today. 2010; 15(17):773-80. [DOI:10.1016/j.drudis.2010.06.009] [PMID]

[3] Påhlsson P, Spitalnik S. The role of glycosylation in synthesis and secretion of $\beta$-amyloid precursor protein by Chinese hamster ovary cells. Arch Biochem Biophys. 1996; 331(2):177-86. [DOI:10.1006/abbi.1996.0296] [PMID]

[4] Grabenhorst E, Schlenke P, Pohl S, Nimtz M, Conradt HS. Genetic engineering of recombinant glycoproteins and glycosylation pathway in mammalian host cells. Glycoconj J. 1999; 16(2):81-97. [DOI:10.1023/A:1026466408042] [PMID]

[5] Vandenborre G, Smagghe G, Ghesquiere B, Menschaert G, Rao RN, Gevaert K, et al. Diversity in protein glycosylation among insect species. PLOS One. 2011; 6(2):e16682. [DOI:10.1371/journal.pone.0016682] [PMID] [PMCID] 
[6] Strickland E, Qu B-H, Millen L, Thomas PJ. The molecular chaperone Hsc70 assists the in vitro folding of the Nterminal nucleotide-binding domain of the cystic fibrosis transmembrane conductance regulator. J Biol Chem. 1997; 272(41):25421-4. [DOI:10.1074/jbc.272.41.25421] [PMID]

[7] Kleizen B, Braakman I. Protein folding and quality control in the endoplasmic reticulum. Curr Opin Cell Biol. 2004; 16(4):343-9. [DOI:10.1016/j.ceb.2004.06.012] [PMID]

[8] Schröder M, Kaufman RJ. The mammalian unfolded protein response. Annu Rev Biochem. 2005; 74:739-89. [DOI:10.1146/ annurev.biochem.73.011303.074134] [PMID]

[9] Schröder M. The unfolded protein response. Mol Biotechnol. 2006; 34(2):279-90. [DOI:10.1385/MB:34:2:279]

[10] Braakman I, Bulleid NJ. Protein folding and modification in the mammalian endoplasmic reticulum. Annu Rev Biochem. 2011; 80:71-99. [DOI:10.1146/annurev-biochem-062209-093836] [PMID]

[11] Ghasemi F, Zomorodipour A, Karkhane AA, Khorramizadeh MR. In silico designing of hyper-glycosylated analogs for the human coagulation factor IX. J Mol Graph Model. 2016; 68:39-47. [DOI:10.1016/j.jmgm.2016.05.011] [PMID]

[12] Weerapana E, Imperiali B. Asparagine-linked protein glycosylation: From eukaryotic to prokaryotic systems. Glycobiology. 2006; 16(6):91-101R. [DOI:10.1093/glycob/cwj099] [PMID]

[13] Liu Y, Nguyen A, Wolfert RL, Zhuo S. Enhancing the secretion of recombinant proteins by engineering $\mathrm{N}$-glycosylation sites. Biotechnol Prog. 2009; 25(5):1468-75. [DOI:10.1002/ btpr.241] [PMID]

[14] Di Scipio RG, Kurachi K, Davie EW. Activation of human factor IX (Christmas factor). J Clin Invest. 1978; 61(6):1528-38. [DOI:10.1172/JC1109073] [PMID] [PMCID]

[15] Kurachi K, Davie EW. Isolation and characterization of a cDNA coding for human factor IX. Proc Natl Acad Sci . 1982; 79(21):6461-4. [DOI:10.1073/pnas.79.21.6461] [PMID] [PMCID]

[16] Arruda VR, Hagstrom JN, Deitch J, Heiman-Patterson T, Camire RM, Chu K, et al. Posttranslational modifications of recombinant myotube-synthesized human factor IX. Blood. 2001; 97(1):130-8. [DOI:10.1182/blood.V97.1.130] [PMID]

[17] Begbie ME, Mamdani A, Gataiance S, Eltringham-Smith LJ, Bhakta V, Hortelano G, et al. An important role for the activation peptide domain in controlling factor IX levels in the blood of haemophilia B mice. Thromb Haemost. 2005; 94(12):1138-47. [DOI:10.1160/TH04-03-0201] [PMID]

[18] Chang J, Brock J, Griffith M, Monroe D. Glycosylation of the activation peptide of factor IX determines plasma half-life. J Thromb Haemost. 2007; 5(Suppl. 2). [DOI:10.1111/j.1538-7836.2007.tb00914.x]

[19] Bolt G, Bjelke J, Hermit M, Hansen L, Karpf D, Kristensen C. Hyperglycosylation prolongs the circulation of coagulation factor IX. J Thromb Haemost. 2012; 10(11):2397-8. [DOI:10.1111/j.1538-7836.2012.04911.x] [PMID]

[20] Gagneux P, Varki A. Evolutionary considerations in relating oligosaccharide diversity to biological function. Glycobiology. 1999; 9(8):747-55. [DOI:10.1093/glycob/9.8.747] [PMID]
[21] Vatandoost J, Bos MH. Efficient expression of functional human coagulation factor IX in stably-transfected Drosophila melanogaster S2 cells; comparison with the mammalian CHO system. Biotechnol Lett. 2016; 38(10):1691-8. [DOI:10.1007/s10529-016-2156-6] [PMID]

[22] Liu CY, Kaufman RJ. The unfolded protein response. J Cell Sci. 2003; 116(10):1861-2. [DOI:10.1242/jcs.00408] [PMID]

[23] Helenius A, Aebi M. Roles of N-linked glycans in the endoplasmic reticulum. Annu Rev Biochem. 2004;73(1):1019-49. [DOI:10.1146/annurev.biochem.73.011303.073752] [PMID]

[24] Sareneva T, Pirhonen J, Cantell K, Kalkkinen N, Julkunen I. Role of N-glycosylation in the synthesis, dimerization and secretion of human interferon-ץ. Biochem J. 1994; 303(3):83140. [DOI:10.1042/bj3030831] [PMID] [PMCID]

[25] Lodish H, Berk A, Zipursky SL, Matsudaira P, Baltimore D, Darnell J. Protein glycosylation in the ER and Golgi complex. In: Lodish H, Berk A, Zipursky SL, Matsudaira P, Baltimore D, Darnell J, editors. Molecular Cell Biology, $4^{\text {th }}$ edition. New York: W. H. Freeman and Company; 2000.

[26] Gil GC, Velander WH, Van Cott KE. Analysis of the Nglycans of recombinant human Factor IX purified from transgenic pig milk. Glycobiology. 2008; 18(7):526-39. [DOI:10.1093/glycob/cwn035] [PMID] [PMCID] 